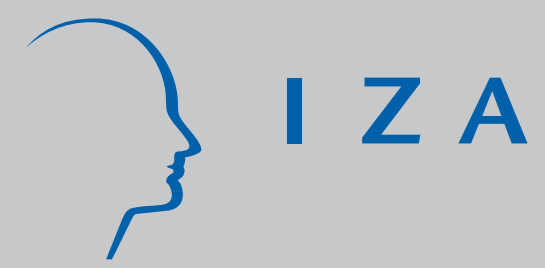

IZA DP No. 8590

Successful Scientific Replication and Extension of Levitt (2008):

Child Seats Are Still No Safer than Seat Belts

Lauren E. Jones

Nicolas R. Ziebarth

October 2014 


\title{
Successful Scientific Replication and Extension of Levitt (2008): Child Seats Are Still No Safer than Seat Belts
}

\author{
Lauren E. Jones \\ Cornell University, PAM \\ and Martin Prosperity Institute \\ Nicolas R. Ziebarth \\ Cornell University, PAM, \\ DIW Berlin and IZA
}

\section{Discussion Paper No. 8590 \\ October 2014}

\author{
IZA \\ P.O. Box 7240 \\ 53072 Bonn \\ Germany \\ Phone: +49-228-3894-0 \\ Fax: +49-228-3894-180 \\ E-mail: iza@iza.org
}

\begin{abstract}
Any opinions expressed here are those of the author(s) and not those of IZA. Research published in this series may include views on policy, but the institute itself takes no institutional policy positions. The IZA research network is committed to the IZA Guiding Principles of Research Integrity.

The Institute for the Study of Labor (IZA) in Bonn is a local and virtual international research center and a place of communication between science, politics and business. IZA is an independent nonprofit organization supported by Deutsche Post Foundation. The center is associated with the University of Bonn and offers a stimulating research environment through its international network, workshops and conferences, data service, project support, research visits and doctoral program. IZA engages in (i) original and internationally competitive research in all fields of labor economics, (ii) development of policy concepts, and (iii) dissemination of research results and concepts to the interested public.
\end{abstract}

IZA Discussion Papers often represent preliminary work and are circulated to encourage discussion. Citation of such a paper should account for its provisional character. A revised version may be available directly from the author. 
IZA Discussion Paper No. 8590

October 2014

\section{ABSTRACT}

\section{Successful Scientific Replication and Extension of Levitt (2008): Child Seats Are Still No Safer than Seat Belts}

Using US fatality data from 1975 to 2003, Levitt (2008) shows that child safety seats do not significantly reduce fatalities for children aged two to six as compared to standard seat belts. Although we were unable to gain access to the original programs and dataset used, we were able to replicate Levitt's (2008) findings almost exactly. We extend Levitt (2008) by showing that the findings also hold for the years 2004 to 2011 despite changing driver characteristics and restraint use patterns. We fail to find evidence that SUVs provide additional safety for children.

JEL Classification: I18, I31, Z13, Q54

Keywords: $\quad$ scientific replication, Steven Levitt, child safety seats, improper use, SUVs, fatalities, FARS

Corresponding author:

Nicolas R. Ziebarth

Cornell University

Policy Analysis and Management (PAM)

106 Martha van Rensselaer Hall

Ithaca, NY 14853

USA

E-mail: nrz2@cornell.edu 


\section{Introduction}

In the US, as well as in over 90 countries worldwide, traffic safety regulations require use of specific, approved child safety seats for children in automobiles (WHO, 2013). Currently, all US states mandate the use of child safety seats. Forty-three states require the use of child safety seats until at least age four, but statutory age and weight regulations have increased significantly over time. In the US, the average age at which children are required to be in a child safety seat increased from an average of 2 years old in the 1980s, to an average of 5 in 2007. For first time offenders, the variation in fines for no use ranges from a \$20 (West Virginia) up to \$500 (Nevada), with a mass point around \$100 (IIHS, 2013).

Despite the prevalence and increasing stringency of these laws, there is evidence that child seats may not be any more effective than seatbelts at preventing children's death and severe injury. Using 1975 to 2003 data from the US Fatality Analysis Reporting System (FARS), Levitt (2008) shows empirically that among children aged two to six, the use of child safety seats does not significantly reduce the probability of a fatality in accidents relative to traditional seatbelts. ${ }^{1}$ This finding casts serious doubts on the effectiveness of child safety seats, despite the common acceptance of and strong support for the traffic safety regulation in the public and among public health scientists (cf. Zaza et al., 2001). If child safety seats do not provide any safety premium over standard seatbelts, then laws that require citizens to buy and use child seats, along with the costs of their enforcement, represent a costly and welfare-decreasing state regulation. It is worthwhile to note that, to date, no (economic) study has seriously challenged Levitt’s (2008) findings.

Because of the high practical relevance of this question we endeavor to replicate Levitt's (2008) original findings, and to test whether Levitt's (2008) findings also apply to a more recent time period, from 2004 to 2011. The latter contribution is important since the last decade has seen potential safety improvements generated by manufacturer and consumer trends in traffic safety and road conditions. We provide an extended discussion of how results from the contemporary era are affected by such changing conditions.

We additionally update and enrich Levitt's (2008) analysis by investigating the impact on restraint effectiveness of two specific traffic safety developments: first, the SUV “arms race"—which makes roads less safe since accidents involving passenger cars and SUVs have an increased fatality probability (White, 2004; Daly et al., 2006, Small and Van Dender, 2007; Li, 2012; Klier and Linn, 2012; Busse et al. 2013); and second, the misuse of child safety seats (Howland et al., 1965; Bull et al., 1988). We investigate how these two traffic phenomena - the SUV arms race and improper use of child seats—could mitigate or strengthen Levitt's (2008) findings on the effectiveness of child safety seat vs. traditional seat belt use.

\footnotetext{
${ }^{1}$ Levitt and Doyle (2010) show that this result also holds for serious injuries. However, they find that child safety seats lead to a significant $25 \%$ reduction in light injuries among two to six year old children.
} 


\section{Scientific Replication and Extension of Levitt (2008) \\ 2.1 Replication of Levitt (2008): Data and Methods Used}

Levitt (2008) makes use of US FARS data from 1975 to 2003. The dataset includes the universe of all accidents in which at least one person died. Moreover, it includes information on the type of restraint used by each vehicle occupant.

We did not have access to the program code used by Steven Levitt, nor did we have access to the specific dataset used in Levitt (2008). This replication is based solely on the descriptions and explanations in Levitt (2005) and Levitt (2008). After accessing the FARS data, we followed the description of how the author restricted the data as closely as possible. ${ }^{2}$ Due to the number of restrictions imposed, we were unable to exactly replicate the working dataset. While our total sample has 38,456 observations, his has only 37,635.

As explained in Levitt (2008), the econometric approach employed regresses a binary indicator of whether a child died in a crash or not on the main variables of interest. The main variables of interest consist of a set of dummies for restraint use: (i) no restraint, (ii) child safety seat, (iii) lap-only belt, and (iv) lap and shoulder belt. In addition, a rich set of vehicle and driver characteristics are used as controls. All models are estimated as linear probability models.

This simple regression intends to explain the statistical relationship between the type of restraint used and the probability that a child dies in a fatal car accident, controlling for observables. The accidents included in the FARS data, however, do not provide a random sample of American vehicles and occupants. Since restraint use may affect the probability of dying in a crash, and since both restraint use and accident fatalities may be related to a third, unobserved variable, the probability of being included in the FARS data is not independent of restraint use. Levitt (2008) adopts the Levitt and Porter (2001a) approach to correct for this sample selection issue. The simple idea is to restrict the sample to two-car crashes where a death occurred in the second vehicle involved. The sample selection issue is then resolved under the assumption that restraint use in vehicle A does not affect the probability that an occupant dies in vehicle B, given both vehicles are involved in an accident.

Columns (1) through (4) of Table 1 show the exact replication of Table 3 in Levitt (2008). However, in the interest of space, we only show results from the fully controlled model and the specification without any controls (columns (1), (3), (4), and (6) in the Levitt paper). Columns (1) and (2) in Table 1 make use of the full sample without the sample selection correction, while columns (3) and (4) solely focus on the subset of twocar crashes with a death in the other car. Columns (1) and (3) regress the child death probability solely on the set of restraint use dummies, while columns (2) and (4) additionally control for a wide range of background

\footnotetext{
${ }^{2}$ Levitt (2008) writes that he drops crashes in which the only fatalities were pedestrians, motorcyclists, or occupants of nonstandard vehicles. Furthermore, he limits the analysis to occupants of automobiles, minivans and SUVs with model years older than 1969. Next, he discards observations with missing values on relevant variables and cases in which the occupant did not sit in the first three rows of the vehicle. Finally, he restricts the sample to children between the age of two and six.
} 
information as indicated in the rows of Table 1. In all models employed, the reference category is no restraint, such that the estimates for each restraint type indicate the change in death probability relative to being unrestrained. Given a child is unrestrained and involved in an accident with a fatality, the baseline probability that the child dies is $27 \%$.

\section{[Insert Table 1 about here]}

Although Levitt's (2008) full sample has 800 fewer observations than ours, the point estimates for all coefficients displayed in the first two columns of our Table 1 are almost identical to Levitt's (2008) coefficients. For example, in column (1) of his table, Levitt (2008) reports a point estimate for child seat of 0.112, which is significant at the $1 \%$ level. Our equivalent estimate in column (1) of Table 1 shows a coefficient -0.1144, also significant at the 1\% level. Table A1 in the Online Appendix formally tests the statistical difference between ours and Levitt's (2008) restraint use coefficients in the simple model with all covariates. The differences are negligible.

One can summarize the results displayed in the first two columns of Table 1 as follows: (i) using a child safety seat, a lap and shoulder belt, or a just a lap belt reduces the likelihood that a child dies in a fatal accident by about 10 ppt. or 30\% as compared to being unrestrained; (ii) controlling for a wide range of background information barely changes the point estimates; and (iii) the differences between our point estimates and Levitt's (2008) are very small and not statistically significant. Our replication results confirm Levitt's main finding: child safety seats provide no additional safety benefit as compared to shoulder and lap or lap-only belts. It should be noted that the difference in the size of the estimates in column (2) of Table 1 (child seat vs. lap and shoulder seat) is only 0.015 or $5 \%$ of the mean death rate. However, the standard errors of both estimates are 0.007, and thus sufficiently large to hide small differences. To be more precise, given the sample size, with $95 \%$ probability one would only be able to identify differences of $2.7 p p t$. or greater, or $10 \%$ of the unrestrained death rate. Nonetheless, when we conduct F-tests comparing the seatbelt coefficients to the child safety coefficients, we find no significant differences. Note also that the all differences between the seatbelt and child seat estimated coefficients are always in favor of seatbelts.

The models in columns (3) and (4) of Table 1 only use a subset of observations to correct for sample selection and use about 2,000 fewer observations than Levitt's (2008) sample. ${ }^{3}$ Consequently, the point estimates differ slightly, but the main findings are again very robust (see Table A1): use of any restraint type reduces the probability that a child dies in a severe accident, where an occupant dies in the other car, by about

\footnotetext{
${ }^{3}$ Levitt (2005) writes that "for the sample selection correction, we created a dummy variable equal to one if someone died in another vehicle involved in the crash.” This implies that all observations in the selection corrected sample should derive from crashes with at least two vehicles involved. However, in Levitt's (2008) results, a coefficient estimate is reported for the onecar crash variable. We followed Levitt (2005) in defining the selection corrected sample and therefore have no one-car crash victims included. The deviation in sizes between Levitt (2008) and our samples is likely due to the extra inclusion of one-car crash victims in Levitt’s sample.
} 
5ppt. on a 7 percent average fatality rate - about a $60 \%$ reduction. Any statistically significant differences between restraint type coefficients disappear when our analysis is limited to the selection corrected sample.

\subsection{Extension of Levitt (2008): Do the Results Hold Up in the “Arms Race” Era 2004-2011?}

Columns (5) to (8) of Table 1 extend Levitt's (2008) analysis by adding data from the years 2004 to 2011. We add a post2003 dummy to the analysis and interact it with all restraint use variables of interest to identify whether restrain effectiveness has changed in the post-2003 period. The results reveal the following: (i) in the modern era, relative to unrestrained children, children in safety belts and child seats appear even less likely to die, i.e., restraint use in general seems to have become more effective; (ii) in the post-2003 period, correction for observables does matter. When controlling for a wide range of background characteristics, the coefficients significantly decrease in size. Still, the effects are significant and large, given that the mean fatality rate in the modern era for unrestrained children is about 33\%: for a 2 to 6 year old child, both traditional seat belts and child safety seats reduce the probability of dying in a fatal accident by about $50 \%$ relative to being unrestrained; (iii) the selection-corrected models in columns (7) and (8), with just 13,550 observations, lack statistical power when differentiating between the pre- and post-2003 time periods. However, when we partition the data and estimate models on the 2004 to 2011 selection corrected sample we find that restraints reduce the likelihood of dying in a crash by about a 70\% ${ }^{4}$; and (iv), the main finding and conclusion of Levitt (2008) also holds in more recent years under changing traffic conditions: when it comes to preventing fatalities, child safety seats are not more effective than simple lap and shoulder restraints. ${ }^{5}$

\section{Restraint Use and Effectiveness in the Modern Era \\ 3.1 Increased Effectiveness of Restraint Use: An Artifact of a More Negatively Selected Group of Parents Who Do Not Restraint Their Kids?}

The results in Table 1 beg the question: are restraints becoming more effective with time? ${ }^{6}$ Figure $1 \mathrm{a}$ plots the rates of restraint use over time for children between ages 2 and 6 years, given they were involved in a fatal accident. The most striking observation is the strong, almost linear, decline in the share of children who are not restrained. In 1980 almost 100\% of all 2 to 6 year olds in the sample were unrestrained. This proportion

\footnotetext{
${ }^{4}$ The coefficient estimates for the selection corrected models estimated on the 2004-2011 data only are $-0.0828 * * *$ for child seat and $-0.0759^{* * *}$ for lap and shoulder belt.

${ }^{5}$ The F-tests reported in Table 1 compare each seatbelt coefficient estimate to the child seat coefficient; in columns (5) to (8), we conduct separate F-tests for the pre- and post-2003 periods. The differences are by and large statistically insignificant; the only statistical difference we identify is in regression (6). Lap and shoulder belts appear significantly more effective than child seats in the pre-2003 period when covariates are considered, but the difference is insignificant in all other model specifications. In a robustness check, we also interacted an indicator of whether the child sat in the first row with all types of restraint use (results upon request): the findings show that sitting in the front row is a lot more dangerous, but that both seatbelts and child safety seats mitigate the risk about equally well.

${ }^{6}$ Changing driver and road conditions in the post-2003 period could account for the result. An alternative explanation would be that due to technical change and safer cars, the severity of crashes in which at least one person died has been increasing over time. Beyond the discussion here, we also estimated all our models by interacting all covariates with the post-2003 indicator, using a series of different data cut-offs to partition the data, and including state-specific linear time trends, none of which significantly changed our results.
} 
had dropped to about $50 \%$ by the mid-1990s and to below $20 \%$ by 2010 . It is obvious that, in the modern era, the group of children who remain unrestrained are a selective sample and that their restraint use patterns are driven by a select group of parents or guardians. ${ }^{7}$ If the marginal parent to take up restraint use is arguably less safety-conscious than the average restraint user, average driver quality among non-restraint users is decreasing over time.

\section{[Insert Figures 1a and 1b about here]}

Figure A1 in the Online Appendix provides evidence that the characteristics of drivers using different child restraint technologies is changing over time. For four characteristics, the figure plots the proportion of drivers using each restraint type for the child in their car with the given characteristic. The figure shows that, over time, drivers who do not restrain their children have become younger, more likely to have consumed alcohol or have a previous major violation, and more likely to be unrestrained themselves than the average driver in the sample. The figure reinforces the hypothesis outlined above and suggests that the quality of drivers who do not restrain a child has decreased over time, a result that may explain the finding of increased restraint effectiveness after 2003.

\subsection{Restraint Use Development: Implications for Child Safety Seat vs. Seat Belt Effectiveness}

Figure 1a shows that, within FARS $\operatorname{data}^{8}$, the usage of both restraint types strongly increased from $0 \%$ in 1980 to about 25\% in 2000. Since then, however, traditional lap and shoulder belt use remained stable, even decreased slightly, while child safety seat use strictly increased to more than $60 \%$ in 2010 . These divergent trends may reflect a selection story, which is supported by the fact that post-2003 era effectiveness estimates significantly decrease once controls for observables are added. One could assume that more "responsible" parents are better drivers, more likely to use child safety seats over seatbelts, and less likely to have fatal accidents.

Selection on unobservables between child safety seat and traditional belt users may introduce two potential sources of biases: First, child safety seat users would be less likely than seatbelt users to be included in the FARS fatality sample. However, to the extent that the probability of having a fatal accident is determined by the second car causing the accident in two-car crashes, this sample selection issue is taken care of by the Levitt and Porter (2001b) correction. Second, if the driving quality among the sample of child safety seat users improved relative to seatbelt users, the identified effects in the recent era are likely biased upward relative to the earlier period. Positive selection into child seat use implies that child death would be less likely

\footnotetext{
7 Among the selection corrected sample, only about $40 \%$ of children were unrestrained in the mid-1980s. The fraction of children who were unrestrained dropped to 20\% in the mid-1990s, and to only about 5\% by 2010.

${ }^{8}$ Recall that FARS data is a selected sample of all fatal crashes in the US and does not represent the average driver. Hence the reported trends and usage rates are conditional on cars involved in fatal accidents. The reported numbers are likely a mix of true underlying changes in restraint use and possible changes in the composition of cars involved in fatalities.
} 
among the sample of child safety seat users relative to seat belt users, regardless of restraint type use. Note that the regression models include year dummies which should capture systematic changes in driver quality over time.

Figure A1 helps dispel some of the concern about selection between seatbelt users and child safety seat users. With the exception of age, the driver characteristic trends among child safety seat users match the trends among seat belt users quite closely. Further, since positive selection into child safety seat use would result in upward biased effectiveness estimates, such a selection pattern would not jeopardize the main finding. ${ }^{9}$ The Ftests comparing different restraint types to one another do not reveal significant differences in the selection corrected models. Finally, it is likely that much of the driver age variation in seatbelt use versus child seat use is due to variation in state-level laws regulating the age until which child safety seat use is mandatory. Indeed, the average age of children in the sample who are restrained in child seats is about 3 , while those restrained by traditional seatbelts are about 4.5 years old. ${ }^{10}$

\subsection{Role of SUVs and Improper Use in Restraint Effectiveness}

Figure $1 \mathrm{~b}$ describes another recent development in road safety conditions: the share of traditional passenger cars versus SUVs on the road. Passenger car use in the sample declined from about 70\% in 1980 to about $40 \%$ in 2010 . Today, about $50 \%$ of the sample is riding in minivans or SUVs at the time of a crash. One observes a particularly strong increase in the use of SUVs since the year 2000-a near doubling from 17 to $31 \%$. The increasing prevalence of SUVs involved in crashes leads us to wonder whether child safety restraint effectiveness is enhanced or diminished when they are used in a crash involving an SUV.

\section{[Insert Table 2 about here]}

The results in Table 2 formally show how the interplay between SUV and restraint use affects safety in the 1991 to 2011 period. Columns (1) and (3) show how restraint type effectiveness changes when the child is riding in an SUV. Interestingly, we do not find evidence that SUVs use alone reduce the probability that a child dies in a crash-in general and in the selection correction approach in column (3). However, in the naïve model in column (2), there is some evidence that child safety seat use in combination with SUV use reduces child fatalities by an additional 4ppt. or $25 \%$ beyond child seat use alone, while seatbelt use does not appear

\footnotetext{
${ }^{9}$ To net out the impact of structural changes in driver quality, we also run models for all years using crash fixed effects (in addition to the ones reported in Table A2). In the full sample, the restraint coefficients slightly increase in size, remain highly significant, but do not differ from one another. In the selection-corrected sample, the coefficient point estimates hardly change with the inclusion of fixed effects.

${ }^{10}$ We tried partitioning the sample by age and re-estimating the models to determine whether child seat versus seatbelt effectiveness depends on child age. For children who are 2 or 3 at the time of the accident, seatbelts and child seats appear equally effective in preventing death; for 4, 5 and 6 year olds, our results (available upon request) suggest that seatbelts might be slightly more effective than child seats at preventing death.
} 
additionally effective in SUVs. ${ }^{11}$ However, once selection into the sample of fatalities is corrected for, the child seat safety premium associated with SUV use disappears. In column (3), the coefficient estimates on both the seat belt and child seat interaction terms are relatively small in magnitude, almost identical, and not significantly different from 0 . Thus, overall, there is no evidence that SUVs prevent fatalities better than other cars, even with the use of restraints.

Lastly, we make use of an explanatory factor that was included in the survey between 1994 and 2007: improper child seat and seat belt use. ${ }^{12}$ It is estimated that more than half of child safety seats are improperly used (Children's Safety Network, 2005); improper restraint use has also gained media attention (New York Times, 2013). Column (2) of Table 2 illustrates that the safety gains from using lap and shoulder belts are completely offset by their improper use, such that improper use appears as dangerous as no use. Strikingly, improper child safety seat use appears significantly less safe than no restraint. While child safety seat use is associated with a 15 ppt. decrease in the probability of death, the effect of improper use completely overwhelms the safety gain, resulting in a net increase in death probability of about 14 ppt. On a base fatality rate of about $20 \%$, this amounts to about a $75 \%$ increase in the likelihood of death associated with improper use of child seats.

However, there are two main issues with this naïve regression. First, the question of selection bias is again an important one in this discussion. Second, reporting of improper use may be correlated with the probability of death in a crash. For example, it is plausible to assume that safety seat use is significantly more likely to be reported as improper if the child died. In the extreme, if the safety seat use of all children who died were (incorrectly) specified as improper, then child death and improper use would be perfectly correlated. We attempt to address this potential measurement issue by including crash-level fixed effects in the models to control for reporting behavior of the attending police officer (see Table A2 in the Online Appendix). The identifying variation in the crash fixed effects models could either stem from multiple children in one car or multiple children in different cars, as long as two children are involved in an accident with a fatality. ${ }^{13}$ While the addition of crash fixed effects cause the standard errors of the coefficient estimates to inflate, the coefficient estimates in the selection corrected model are barely changed. If the result was due entirely to reporting bias, we would expect this approach to reduce the estimated magnitudes as long as reporting bias is

\footnotetext{
${ }^{11}$ For all results presented in Table 2, we collapse the lap and shoulder belt category and the lap-only belt category due to the relatively few children using lap-only belts in more recent years.

12 Thus, the models in column (2) and (4) only make use of the years 1994 to 2007 and have only 25,622 and 8,264 observations, respectively.

${ }^{13}$ Note that this approach does not control for reporting errors when only one kid dies in the accident and child death is correlated with incorrect improper use reporting. Ideally, one would need to restrict the sample to fatal accidents where two kids died. Then the crash fixed effects would properly net out reporting heterogeneity by policer officers since the effects would solely be identified by within-accident variation of improperly used safety seats. Due to sample size, we are unable to implement this approach.
} 
moderately reduced by looking within crash. However, it is certain that the result herein should be interpreted with caution.

\section{Discussion and Conclusion}

In this paper, we replicate the results in Levitt (2008) nearly perfectly. According to these findings, child safety seats provide no additional safety advantage over traditional lap and should seat belts. It is important to remember that the current results only apply to fatalities. While Levitt's (2008) original findings that we replicate solely refer to fatalities, Doyle and Levitt (2010) extend them for injuries. In terms of injuries, child safety seats are effective in reducing them, but only for light injuries (Doyle and Levitt, 2010).

We extend Levitt's (2008) analysis and show that the results also hold in the new millennium despite some remarkable developments on Americans roads. For example, child seat safety use has strictly increased while the prevalence of unrestrained children has strictly decreased. We therefore provide a careful analysis of changing driver characteristics among differently restrained children, which may account for conflicting findings in past studies of restraint effectiveness (e.g. Elliot et al., 2006).

Further analyses show that the SUV safety premium disappears once selection into a crash is accounted for, which is an important finding given the commonly-held belief that SUVs are safer. For example, a 2005 National Highway Traffic Safety Administration report using the same FARS data found that properly restrained children in SUVs are significantly less likely to die in a fatal crash (Starnes, 2005). This finding is also important from a welfare perspective since passengers in cars involved in a crash with an SUV are significantly more likely to die. If SUVs do not provide additional safety benefits to occupants, and endanger passengers in other car types, their increasing prevalence on American roads is cause for concern (White, 2004; Anderson, 2008; Li, 2012).

\section{Literature}

Anderson, Michael (2008): "Safety for whom? The effects of light trucks on traffic fatalities," Journal of Health Economics, 27(4: 973-989.

Bull, Marilyn J. and Stroup, Karen Bruner and Gerhart, Susan (1988): “Misuse of Car Safety Seats,” Pediatrics, 81(1): 98-101.

Busse, Meghan R. and Christopher R. Knittel and Zettelmeyer, Florian (2013): "Are Consumers Myopic? Evidence from New and Used Car Purchases," American Economic Review, 103(1): 220-256.

Children's Safety Network (2005): "Child Safety Seats: How Large are the Benefits?" available at http://www.childrenssafetynetwork.org/sites/childrenssafetynetwork.org/files/child_safety_seats_childhood_in jury_cost_prevention.pdf, last accessed on October 7, 2013.

Daly, Lauren, Kallan, Michael J., Arbogast, Kristy B. and Durbin, Dennis R. (2006): "Risk of Injury to Child Passengers in Sport Utility Vehicles,” Pediatrics, 117(1): 9-14.

Elliot, Michael R., Kallan, Michael J., Dennis R. Durbin and Winston, Flaura K. (2006): "Effectiveness of Child Safety Seats vs Seat Belts in Reducing Risk for Death in Children in Passenger Vehicle Crashes," Pediatrics, 160(6): 617-621. 
Howland, Willard J., Curry, Joseph L. and Buffington, Caroll B. (1965): "Fulcrum fractures of the lumbar spine: Transverse fracture induced by an improperly placed seat belt,” JAMA, 193(3): 240-241.

Insurance Institute for Highway Safety (IIHS) (2013): “State Laws". Available at http://www.iihs.org/iihs/topics/laws/safetybeltuse?topicName=child-safety, last accessed on Nov. 10, 2013.

Klier, Thomas and Linn, Joshua (2012):"New-vehicle characteristics and the cost of the Corporate Average Fuel Economy standard," RAND Journal of Economics, 43(1): 186-213.

Levitt, Steven D. (2005): "Evidence that Seat Belts are as Effective as Child Safety Seats in Preventing Death for Children Aged Two and Up," mimeo, Data Appendix, available at: http://pricetheory.uchicago.edu/levitt/Papers/levitt_carseats_farsdata.pdf, last accessed on September 18, 2013.

Levitt, Steven D. (2008): "Evidence that Seat Belts are as Effective as Child Safety Seats in Preventing Death for Children Aged Two and Up,” The Review of Economics and Statistics, 90(1): 158-163.

Levitt, Steven D. and Doyle Junior, Joseph J. (2010): "Evaluating the Effectiveness of Child Safety Seats and Seat Belts in Protecting Children from Injury,” Economic Inquiry, 48(3): 521-536.

Levitt, Steven D. and Porter, Jack (2001a): "Estimating the Effect of Alcohol on Driver Risk Using only Fatal Accident Statistics,” The Review of Economics and Statistics, 83(4): 603-615.

Levitt, Steven D. and Porter, Jack (2001b): “How Dangerous are Drinking Drivers,” Journal of Political Economy, 109(6): 1198-1237.

Li, Shanjun (2012): "Traffic safety and vehicle choice: quantifying the effects of the 'arms race' on American roads,” Journal of Applied Econometrics, 27(1): 34-62.

New York Times, The (2013): “Strapped In, but Still at Risk: Car Seats Remain a Vexing Safety Issue,” October 11, 2013.

Starnes, Marc (2005): "Child Passenger Fatalities and Injuries, Based on Restraint Use, Vehicle Type, Seat Position, and Number of Vehicles in the Crash,“ Mathematical Analysis Division, National Center for Statistics and Analysis, National Highway Traffic Safety Administration, available at http://wwwnrd.nhtsa.dot.gov/Pubs/809784.pdf, last accessed on Oct. 7, 2013.

Small, Kenneth A. and Van Dender, Kurt (2007): "Fuel Efficiency and Motor Vehicle Travel: The Declining Rebound Effect," The Energy Journal, 28(1): 25-52.

White, Michelle J (2004): "’'The Arms Race” on American Roads: The Effect of Sport Utility Vehicles and Pickup Trucks on Traffic Safety," Journal of Law and Economics, 47(2): 333-355.

World Health Organization (2013): “Global Status Report on Road Safety”. Available at http://www.who.int/violence injury prevention/road safety status/2013/en/index.html, last accessed on Nov. 10, 1982.

Zaza, Stephanie, Sleet, David A., Thompson, Robert S., Sosin, Daniel M.,Bolen, Julie C. Bolen and the Task Force on Community Preventive Services (2001): "Reviews of evidence regarding interventions to increase use of child safety seats,” American Journal of Preventive Medicine, 21(4) S. 1: 31-47. 
Figures and Tables

Fiqure 1a: Development of restraint use (1975-2011) Fiqure 1b: Development of vehicle type (1992-2011)
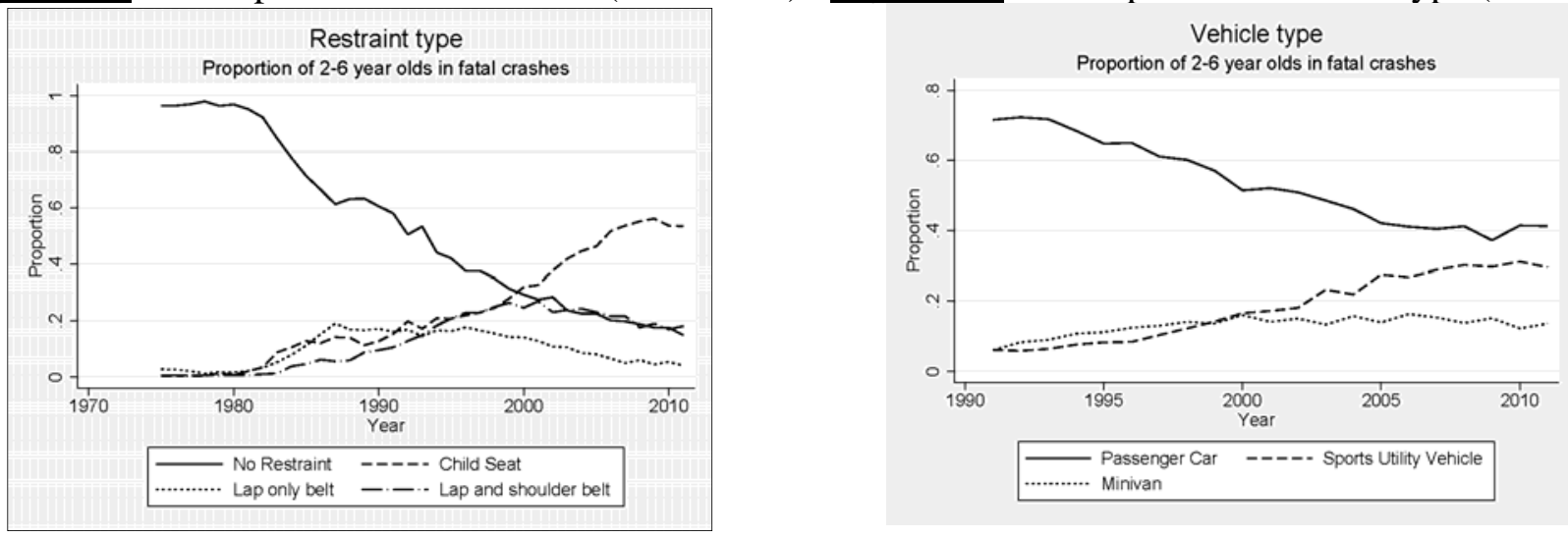

Sources: FARS data, own illustration. 


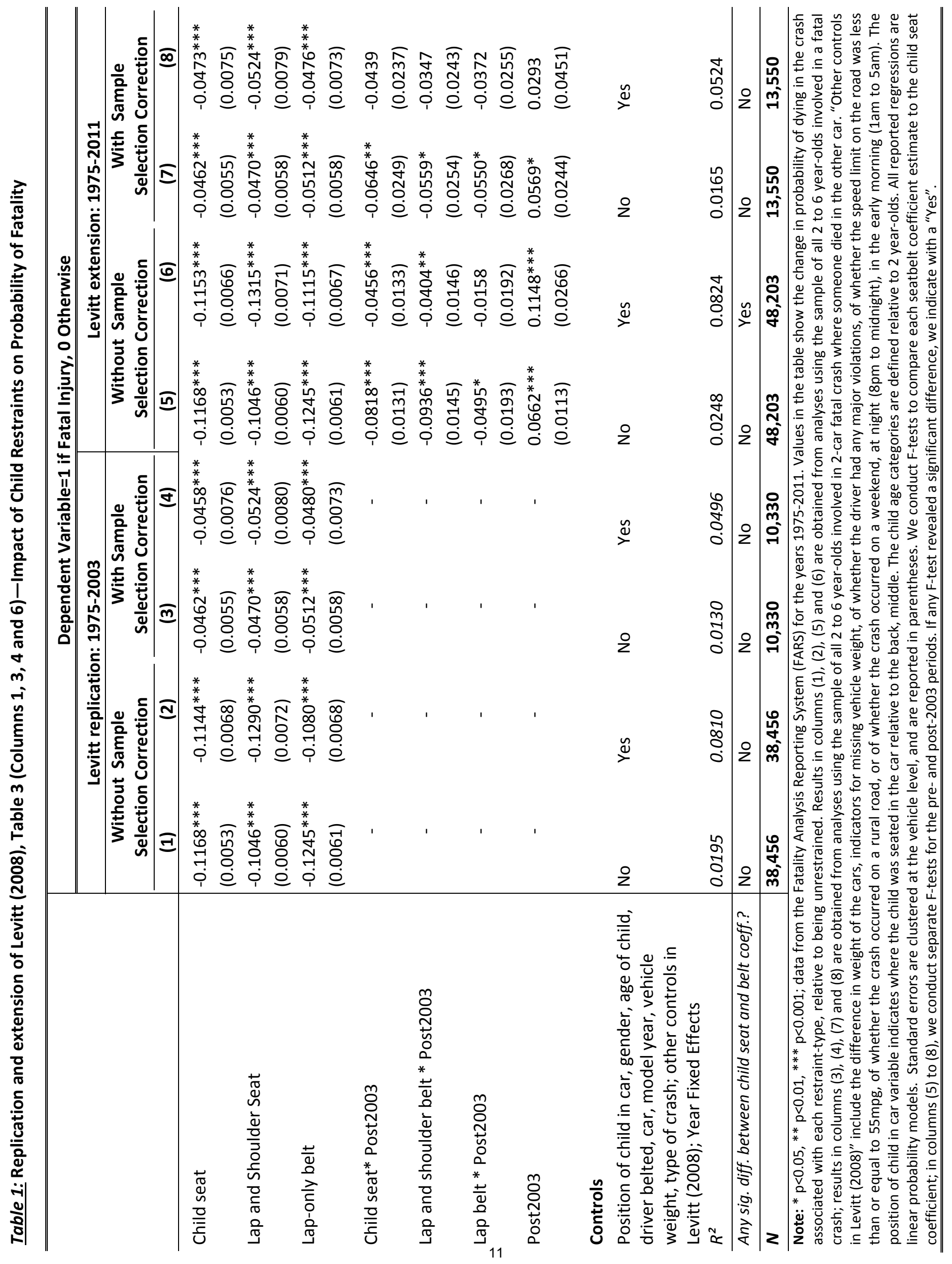


Table 2: Impact of Child Restraints, Their Improper Use, and Their Use in SUVs on Probability of Fatality

\begin{tabular}{|c|c|c|c|c|}
\hline & \multicolumn{4}{|c|}{ Dependent Variable=1 if Fatal Injury, 0 Otherwise } \\
\hline & \multicolumn{2}{|c|}{$\begin{array}{c}\text { Without Sample } \\
\text { Selection Correction }\end{array}$} & \multicolumn{2}{|c|}{$\begin{array}{c}\text { With Sample } \\
\text { Selection Correction }\end{array}$} \\
\hline & (1) & (2) & (3) & (4) \\
\hline Child seat*SUV & $\begin{array}{c}-0.0470 * * \\
(0.0150)\end{array}$ & & $\begin{array}{l}-0.0226 \\
(0.0276)\end{array}$ & \\
\hline Seatbelt*SUV & $\begin{array}{l}-0.0162 \\
(0.0157)\end{array}$ & & $\begin{array}{l}-0.0218 \\
(0.0279)\end{array}$ & \\
\hline SUV & $\begin{array}{c}0.0105 \\
(0.0136)\end{array}$ & & $\begin{array}{c}0.0251 \\
(0.0275)\end{array}$ & \\
\hline Child seat improperly used & & $\begin{array}{c}0.3014 * * * \\
(0.0247)\end{array}$ & & $\begin{array}{c}0.1447 * * \\
(0.0504)\end{array}$ \\
\hline Seatbelt improperly used & & $\begin{array}{c}0.1522 * * * \\
(0.0370)\end{array}$ & & $\begin{array}{c}0.1119 \\
(0.0726)\end{array}$ \\
\hline Child seat & $\begin{array}{c}-0.1310^{* * *} \\
(0.0072)\end{array}$ & $\begin{array}{c}-0.1566 * * * \\
(0.0077)\end{array}$ & $\begin{array}{c}-0.0594 * * * \\
(0.0100)\end{array}$ & $\begin{array}{c}-0.0618^{* * *} \\
(0.0099)\end{array}$ \\
\hline Seatbelt & $\begin{array}{c}-0.1441^{* * *} \\
(0.0066)\end{array}$ & $\begin{array}{c}-0.1538^{* * *} \\
(0.0071)\end{array}$ & $\begin{array}{c}-0.0632^{* * *} \\
(0.0088)\end{array}$ & $\begin{array}{c}-0.0594 * * * \\
(0.0095)\end{array}$ \\
\hline Controls & & & & \\
\hline $\begin{array}{l}\text { Position of child in car, gender, age } \\
\text { of driver, driver belted, car, model } \\
\text { year., vehicle weight, type of crash; } \\
\text { other controls in Levitt (2008); } \\
\text { Year Fixed Effects }\end{array}$ & Yes & Yes & Yes & Yes \\
\hline$R^{2}$ & 0.0861 & 0.0980 & 0.0347 & 0.0449 \\
\hline$N$ & 33,140 & 25,622 & 10,497 & 8,264 \\
\hline
\end{tabular}

Note: ${ }^{*} \mathrm{p}<0.05,{ }^{* *} \mathrm{p}<0.01,{ }^{* * *} \mathrm{p}<0.001$; data from the Fatality Analysis Reporting System (FARS) for the years 1991-2011. Values in the table show the change in probability of dying in the crash associated with each restraint-type, relative to being unrestrained. Results in columns (1) and (2) are obtained from analyses using the sample of all 2 to 6 year-olds involved in a fatal crash; results in columns (3) and (4) are obtained from analyses using the sample of all 2 to 6 year-olds involved in 2-car fatal crash where someone died in the other car. See Table 1. 


\section{Online Appendix}

Table A1: Formal T-test of Differences in Coefficient Estimates

\begin{tabular}{|ccccc|}
\hline & & & \\
& Levitt (2008) & Ziebarth (2013) & Difference & p-value \\
\hline Simple & & & \\
Child seat & -0.132 & -0.114 & -0.018 & 0.0651 \\
Lap belt & -0.108 & -0.108 & $(0.010)$ & 1.00 \\
& & & 0.00 & \\
Lap/Shoulder belt & -0.132 & -0.129 & $-0.010)$ & 0.7747 \\
& & & $(0.010)$ & \\
Selection-corrected & & & -0.008 & 0.4501 \\
Child seat & -0.054 & -0.046 & $(0.011)$ & 0.8414 \\
& & & 0.002 & \\
Lap belt & -0.046 & -0.048 & $(0.010)$ & \\
Lap/Shoulder belt & -0.052 & -0.052 & 0.00 & \\
& & & $(0.011)$ & \\
\hline
\end{tabular}


Table A2: Improper use results with crash fixed effects

\begin{tabular}{|c|c|c|}
\hline & \multicolumn{2}{|c|}{ Dependent Variable $=1$ if Fatal Injury, 0 Otherwise } \\
\hline & $\begin{array}{c}\text { Without Sample } \\
\text { Selection Correction } \\
(1) \\
\end{array}$ & $\begin{array}{c}\text { With Sample } \\
\text { Selection Correction } \\
(2) \\
\end{array}$ \\
\hline \multirow[t]{2}{*}{ Child seat improperly used } & $0.3192 *$ & 0.1303 \\
\hline & $(0.1497)$ & $(0.1367)$ \\
\hline \multirow[t]{2}{*}{ Seatbelt improperly used } & 0.2184 & 0.1410 \\
\hline & $(0.1974)$ & $(0.1673)$ \\
\hline \multirow[t]{2}{*}{ Child seat } & $-0.2502 * * *$ & -0.0634 \\
\hline & $(0.0515)$ & $(0.0767)$ \\
\hline \multirow[t]{2}{*}{ Seatbelt } & $-0.2308 * * *$ & -0.0525 \\
\hline & $(0.0482)$ & $(0.0674)$ \\
\hline \multicolumn{3}{|l|}{ Controls } \\
\hline $\begin{array}{l}\text { Position of child in car; Gender, age } \\
\text { of driver, driver belted; Car, model } \\
\text { year, vehicle weight, type of crash }\end{array}$ & Yes & Yes \\
\hline Year Fixed Effects & Yes & Yes \\
\hline Crash Fixed Effects & Yes & Yes \\
\hline Other controls in Levitt (2008) & Yes & Yes \\
\hline$R^{2}$ & 0.8350 & 0.8787 \\
\hline$N$ & 25,622 & \\
\hline
\end{tabular}

Note: ${ }^{*} \mathrm{p}<0.05,{ }^{* *} \mathrm{p}<0.01,{ }^{* * *} \mathrm{p}<0.001$; data from the Fatality Analysis Reporting System (FARS) for the years 1991-2011. Values in the table show the change in probability of dying in the crash associated with each restraint-type, relative to being unrestrained. Results in columns (1) and (2) are obtained from analyses using the sample of all 2 to 6 year-olds involved in a fatal crash; results in columns (3) and (4) are obtained from analyses using the sample of all 2 to 6 year-olds involved in 2-car fatal crash where someone died in the other car. See Table 1. 
Fiqure A1: Driver characteristics by child restraint type, relative to overall driver characteristics, 1982-2011

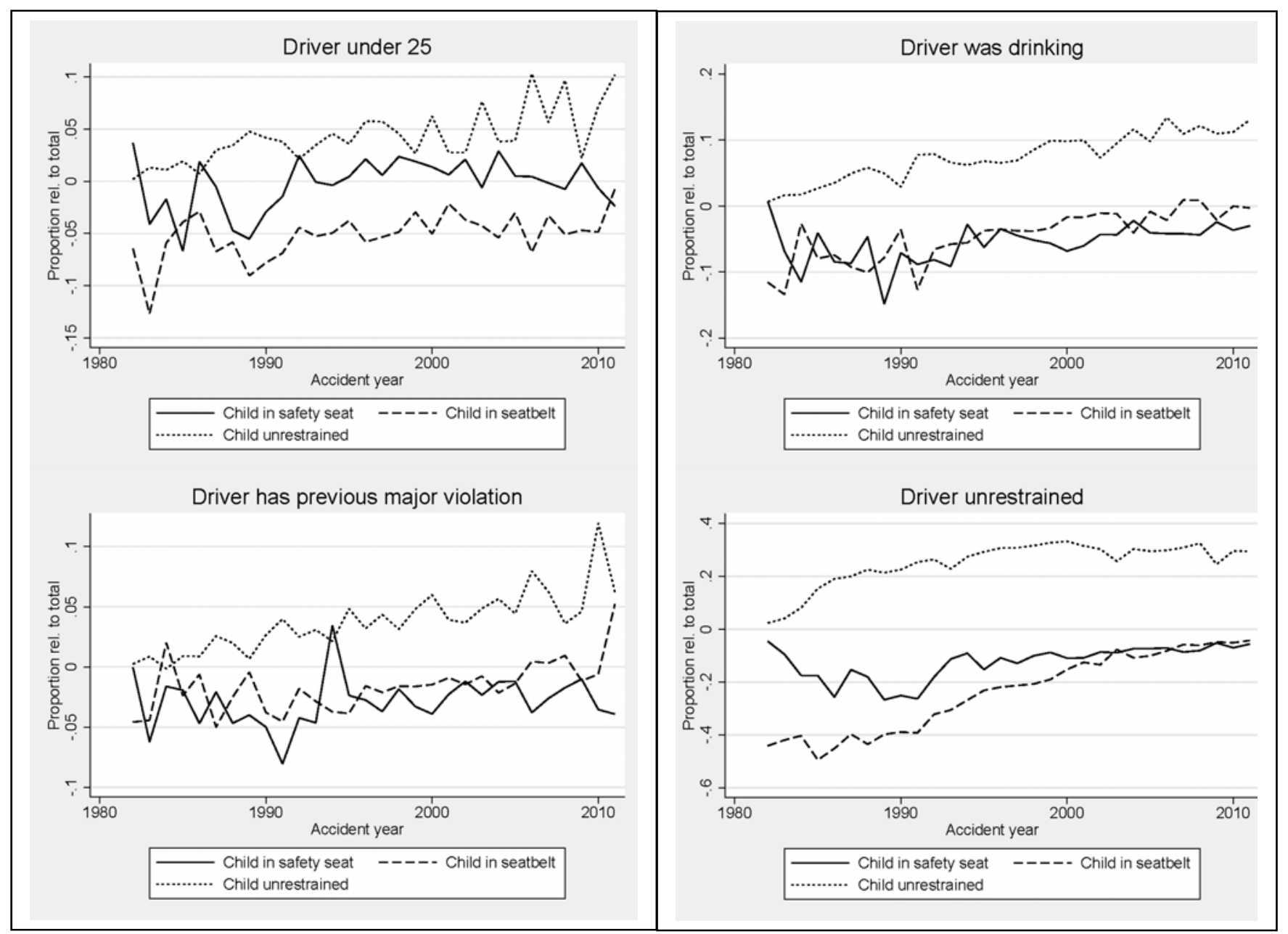

Sources: FARS data, own illustration.

Notes: The characteristic rates among each restraint use category have been normalized to the characteristic rate among all drivers in the accident year, so that a value of 0 indicates no deviation from the yearly average rate in the sample of all drivers. 